\title{
Detection of Novel Fusion Transcript VTI1A-CFAP46 in Hepatocellular Carcinoma
}

\author{
Shunichi Tsuge ${ }^{a} \quad$ Behnam Saberi $^{a}$ b Yulan Cheng $^{\text {a }}$ Zhixiong Wang ${ }^{\text {a, c }}$ \\ Amy Kim $^{a}$ Harry Luu $^{a}$ John M. Abraham ${ }^{a}$ Maria D. Ybanez ${ }^{d}$ \\ James P. Hamilton ${ }^{a}$ Florin M. Selaru ${ }^{a}$ Carlos Villacorta-Martin ${ }^{b}$ \\ Felix Schlesinger $^{e}$ Benjamin Philosophe ${ }^{f}$ Andrew M. Cameron ${ }^{f}$ \\ Qingfeng Zhu ${ }^{\mathrm{g}}$ Robert Anders $^{\mathrm{g}}$ Ahmet Gurakar ${ }^{\mathrm{a}}$ \\ Stephen J. Meltzer ${ }^{a}, d, h$ \\ a Division of Gastroenterology and Hepatology, The Johns Hopkins University School \\ of Medicine, Baltimore, MD, USA; ${ }^{b}$ Division of Liver Diseases, Icahn School of Medicine \\ at Mount Sinai, New York, NY, USA; ' ${ }^{\circ}$ epartment of Gastrointestinal Surgery, The First \\ Affiliated Hospital of Sun Yat-sen University, Guangzhou, China; ${ }^{d}$ Department of Oncology, \\ The Johns Hopkins University School of Medicine, Baltimore, MD, USA; elllumina, San Diego,

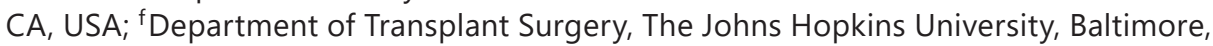 \\ MD, USA; 9 Department of Pathology, The Johns Hopkins University School of Medicine, \\ Baltimore, MD, USA; ${ }^{h}$ Sidney Kimmel Comprehensive Cancer Center, Baltimore, MD, USA
}

\section{Keywords}

Fusion transcript · RNA sequencing · Hepatocellular carcinoma · Hepatoma - Liver transplantation

\begin{abstract}
Background: Hepatocellular carcinoma (HCC) is now the second-highest cause of cancer death worldwide. Recent studies have discovered a wide range of somatic mutations in HCC. These mutations involve various vital signaling pathways such as: Wnt/ $\beta$-Catenin, $\mathrm{p} 53$, telomerase reverse transcriptase (TERT), chromatin remodeling, RAS/MAPK signaling, and oxidative stress. However, fusion transcripts have not been broadly explored in HCC. Methods: To identify novel fusion transcripts in HCC, in the first phase of our study, we performed targeted RNA sequencing (in HCC and paired non-HCC tissues) on 6 patients with a diagnosis of HCC
\end{abstract}

Shunichi Tsuge and Behnam Saberi contributed equally to this work.

Behnam Saberi, MD

Division of Liver Diseases, Icahn School of Medicine at Mount Sinai

Box 1123, 1425 Madison Ave, Room 11-73

New York, NY 10029 (USA)

E-Mail behnam.saberi@mssm.edu 
undergoing liver transplantation. Results: As a result of these studies, we discovered the novel fusion transcript, VTI1A-CFAP46. In the second phase of our study, we measured the expression of wild-type VTI1A in $21 \mathrm{HCC}$ specimens, which showed that 10 of 21 exhibited upregulation of wild-type VTI1A in their tumors. VTI1A (Vesicle Transport via Interaction with t-SNARE homolog $1 A$ ) is a member of the Soluble N-ethylmaleimide-Sensitive Factor (NSF) attachment protein receptor (SNARE) gene family, which is essential for membrane trafficking and function in endocytosis, autophagy, and Golgi transport. Notably, it is known that autophagy is involved in HCC. Conclusions: The link between novel fusion transcript VTI1A-CFAP46 and autophagy as a potential therapeutic target in HCC patients deserves further investigation. Moreover, this study shows that fusion transcripts are worthy of additional exploration in HCC.

(c) 2019 S. Karger AG, Basel

\section{Introduction}

Hepatocellular carcinoma (HCC) is the fifth most common cancer in men and the ninth most common in women, as well as the second most frequent cause of cancer death in both sexes overall [1]. The largest burden of HCC occurs in eastern and southeastern Asia and central and western Africa, which together account for more than $80 \%$ of cases. $50 \%$ of all cases of HCC occur in China alone [1, 2]. Unlike many other cancers, the principal risk factors associated with HCC have, in fact, been elucidated. The key etiologic causes for HCC development include hepatitis B virus (HBV), hepatitis C virus (HCV), alcoholic liver disease, and nonalcoholic fatty liver disease $[3,4]$. With recent advances in genomic sequencing technologies, molecular genetic factors have now also been implicated in HCC development. For example, inflammation mediated by TNF- $\alpha$, IL1- $\beta$, or TGF- $\beta$, cell cycle control by p53, growth factor pathways, and telomerase reactivation through telomerase reverse transcriptase (TERT) have all been recognized as contributory. Additionally, genetic factors are involved in invasion, metastasis, metabolism, and drug resistance of HCC [5].

Fusion transcripts are chimeric RNA molecules resulting from the fusion or rearrangement of two separate genes. One well-described example is the Philadelphia chromosome that occurs in chronic myelogenous leukemia (CML). This is a reciprocal translocation that generates the BCR-ABL fusion gene. This fusion gene, which encodes the BCR-ABL tyrosine kinase, results in abnormal cell proliferation [6]. Recently, chromosomal rearrangements and fusion transcripts have been increasingly described in solid tumors. For example, a fusion between EML4 (Echinoderm Microtubule-associated protein-Like 4) and ALK (Anaplastic Lymphoma receptor tyrosine Kinase) is reported in non-small lung cancer, and ALK inhibitors are currently being evaluated in trials in patients harboring this alteration [7]. The TMPRSS2-ERG fusion transcript is used in the diagnosis and prognostication of prostate cancer [8]. A reciprocal translocation between PLAG1, a developmentally regulated zinc finger gene, and CTNNB1 (beta-catenin) has been reported in a pleiomorphic salivary gland tumor [9]. These fusions illuminated a key mechanism of tumorigenesis and have become a target of increasing research into both diagnostic markers and cancer therapeutics [10-12]. However, unlike leukemias or lymphomas, as well as certain other types of solid cancer, fusion transcripts have not been extensively studied in advanced hepatic fibrosis or HCC.

Herein, we used targeted-transcriptome RNA sequencing (RNA-seq) to identify novel fusion transcripts in HCC, which led us to discover a novel fusion transcript, VTI1A-CFAP46. Vesicle Transport via Interaction with t-SNARE homolog 1A (VTI1A) is a member of the Soluble N-ethylmaleimide-Sensitive Factor (NSF) attachment protein receptor (SNARE) family that is found in complexes with either syntaxin-13 or syntaxin-16 and synataxin- 6 and 


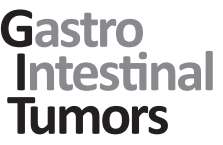

Fig. 1. Algorithm showing the number of patients in phases 1 and 2 of the study. In phase 2 of the study, 15 samples were obtained from HCC lesions, from a total of 13 patients.

\begin{tabular}{l|l}
\hline Gastrointest Tumors 2019;6:11-27 \\
\hline DOI: 10.1159/000496795 & $\begin{array}{l}\text { @ 2019 S. Karger AG, Basel } \\
\text { www.karger.com/gat }\end{array}$ \\
\hline
\end{tabular}

Tsuge et al.: Fusion Transcripts in Hepatocellular Carcinoma

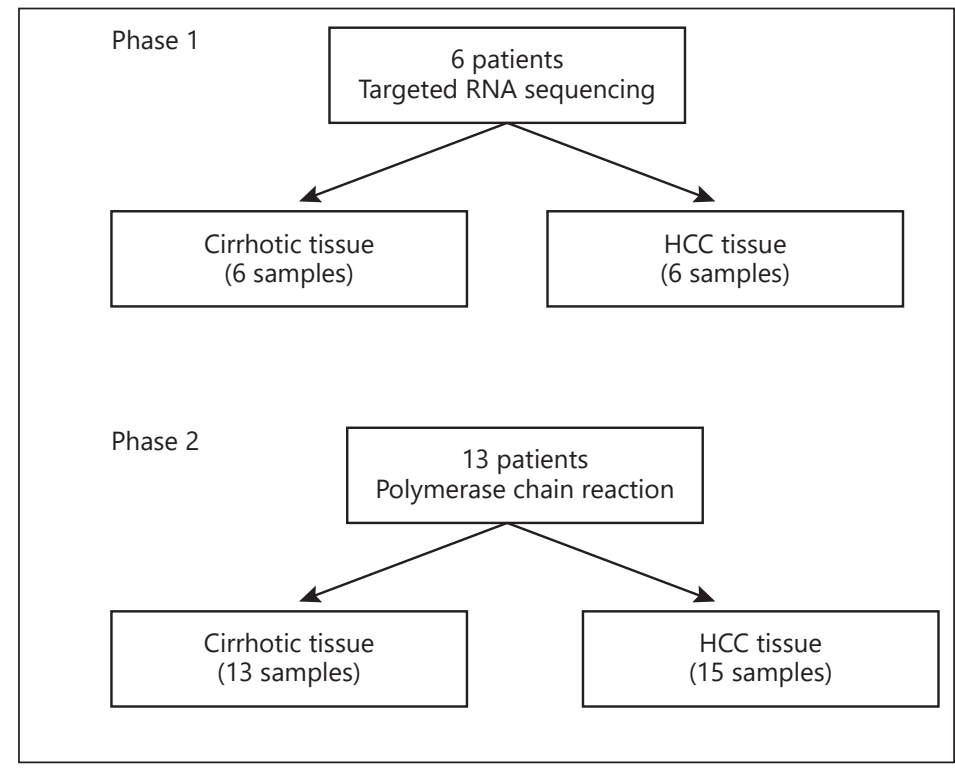

VAMP-4. SNAREs are essential for membrane trafficking and function in endocytosis, autophagy, and Golgi transport $[13,14]$. Notably, these processes have been implicated in hepatocellular carcinogenesis [15, 16]. Cilia and Flagella Associated Protein 46 (CFAP46), previously known as Tetratricopeptide Repeat Domain 40 (TTC40), is a recently described gene whose function is not well known [17]. The identification and characterization of fusion events in HCC promises to deepen our understanding of its underlying pathology, while simultaneously generating promising early diagnostic markers and therapeutic targets, which should help improve outcomes in this deadly malignancy.

\section{Materials and Methods}

Patient Samples and Cell Lines

In the first phase of this study (Fig. 1), HCC specimens and adjacent nonmalignant tissue from 6 patients were obtained at the time of deceased donor liver transplant at the Johns Hopkins Hospital under an Institutional Review Board (IRB)-approved protocol. We extracted RNA from these 6 HCC and 6 paired non-HCC samples. We then performed targeted RNA-seq on these 12 samples. Under the same IRB protocol, in the second phase of the study, we obtained paired HCC and non-HCC tissues from an additional 13 patients 12 patients following liver transplant and 1 patient following liver resection for HCC). Among these 13 patients, 2 had two discrete HCC lesions; thus, in the second phase we added another 15 HCC samples and 13 matched nonmalignant controls. Therefore, in both phases of the study we evaluated a total of 19 patients (total of 40 specimens: 21 HCC and 19 non-HCC samples) (Fig. 1). We also collected and analyzed RNA from two HCC-derived cell lines (97 L, 97 H) [18].

cDNA Library Preparation and Sequencing

Total RNA from specimens was extracted using an RNeasy Mini Kit (QIAGEN). Total RNA was converted into a cDNA library, then selectively enriched for 1,385 cancer-associated genes using the TruSight RNA PanCancer Panel kit according to the manufacturer's instructions (Illumina). The TruSight RNA Pan-Cancer panel is a targeted sequencing strategy that enables measurement of gene expression, variant calling, and fusion detection of cancer-related genes with limited sample quantity. This approach has the ability to detect fusions between any of the 1,385 genes in the panel, but also between any of these genes and other novel fusion partners, for instance FGFR1-X fusions, where X represents any possible gene. All RNA-seq was performed on MiSeq instruments with V3 reagents according to the manufacturer's instructions (Illumina). 
Table 1. Clinical characteristics of HCC patients

\begin{tabular}{|c|c|c|c|c|c|c|c|c|c|}
\hline & $\begin{array}{l}\text { Age/ } \\
\text { sex }\end{array}$ & Etiology & HCV RNA & $\begin{array}{l}\text { Fibrosis } \\
\text { stage }\end{array}$ & $\begin{array}{l}\text { MELD } \\
\text { score }\end{array}$ & $\begin{array}{l}\text { Tumor } \\
\text { recurrence }\end{array}$ & $\begin{array}{l}\text { Pre-LTx } \\
\text { AFP }\end{array}$ & Death & $\begin{array}{l}\text { Follow- } \\
\text { up, days }\end{array}$ \\
\hline \multicolumn{10}{|c|}{ First phase of study: 6 patients } \\
\hline Patient 1 & $64 / \mathrm{M}$ & $\mathrm{HCV} / \mathrm{HIV}$ & Detectable & 3 & 12 & No & 2.4 & No & 532 \\
\hline Patient 2 & $61 / \mathrm{M}$ & $\mathrm{HCV}$ & Undetectable & 4 & 15 & No & 2.6 & Yes & 318 \\
\hline Patient 3 & $68 / \mathrm{M}$ & $\mathrm{HCV}$ & Undetectable & 4 & 10 & No & 4.5 & No & 517 \\
\hline Patient 4 & $64 / \mathrm{M}$ & $\mathrm{HCV} / \mathrm{ETOH}$ & Undetectable & 4 & 11 & No & 4.9 & No & 442 \\
\hline Patient 5 & $48 / \mathrm{M}$ & $\mathrm{HCV}$ & Undetectable & 4 & 10 & No & 8.4 & No & 445 \\
\hline Patient 6 & $63 / \mathrm{M}$ & $\mathrm{HCV} / \mathrm{HBV} / \mathrm{HIV}$ & Undetectable & 4 & 9 & No & 4.2 & No & 437 \\
\hline \multicolumn{10}{|c|}{ Second phase of study: additional 13 patients } \\
\hline Patient 7 & $69 / F$ & NASH & $\mathrm{N} / \mathrm{A}$ & 4 & 8 & No & 3.8 & No & 442 \\
\hline Patient 8 & $51 / \mathrm{M}$ & ЕTOH & $\mathrm{N} / \mathrm{A}$ & 4 & 7 & Yes & 7.2 & No & 427 \\
\hline Patient 9 & $61 / \mathrm{F}$ & HCV & Detectable & 4 & 13 & No & 43.8 & No & 405 \\
\hline Patient 10 & $55 / \mathrm{M}$ & $\mathrm{HCV}$ & Undetectable & 4 & 6 & No & 3.8 & No & 363 \\
\hline Patient 11 & $66 / \mathrm{M}$ & $\mathrm{HCV}$ & Detectable & 4 & 10 & No & 179.3 & No & 387 \\
\hline Patient 12 & $68 / \mathrm{M}$ & HCV & Detectable & 4 & 8 & No & 41.2 & No & 383 \\
\hline Patient 13 & $62 / \mathrm{F}$ & NASH & $\mathrm{N} / \mathrm{A}$ & 4 & 8 & No & 3.7 & No & 339 \\
\hline Patient 14 & $58 / \mathrm{F}$ & $\mathrm{HCV}$ & Detectable & 3 & 6 & No & 10.1 & No & 293 \\
\hline Patient 15 & $54 / \mathrm{F}$ & $\mathrm{HCV}$ & Detectable & 4 & 10 & No & 60.7 & No & 285 \\
\hline Patient 16 & $56 / \mathrm{M}$ & Cryptogenic & $\mathrm{N} / \mathrm{A}$ & 4 & 10 & Yes & 3.5 & No & 160 \\
\hline Patient 17 & $60 / \mathrm{M}$ & HCV & Yes & 3 & 7 & No & 8.4 & No & 125 \\
\hline Patient $18^{\mathrm{a}}$ & $59 / \mathrm{M}$ & $\mathrm{HCV}$ & No & 3 & 14 & No & 1.8 & No & 125 \\
\hline Patient 19 & $54 / \mathrm{M}$ & HBV & $\mathrm{N} / \mathrm{A}$ & 4 & 9 & No & 71.5 & No & 149 \\
\hline
\end{tabular}

HCV, hepatitis C virus; HIV, human immunodeficiency virus; HBV, hepatitis B virus; ETOH, alcoholic liver disease; NASH, non-alcoholic steatohepatitis; MELD, model for end-stage liver disease; LTx, liver transplant; AFP, alpha fetoprotein; N/A, not applicable. ${ }^{a}$ This patient underwent liver resection rather than liver transplant.

\section{Bioinformatics Analysis}

We used The BaseSpace ${ }^{\circledR}$ RNA-Seq Alignment v1.0 suite (Illumina) to analyze the sequence data. This package provides a wrapper for the alignment, summarization, variant calling, and fusion detection methods like STAR, Manta, Cufflinks, Isaac Variant Caller, and Tuxedo Suite (including Bowtie, Bowtie2, and TopHat). As a reference for alignment, we use the UCSC hg19 version of the human genome. First, the BaseSpace RNA-Seq Alignment workflow uses Bowtie to identify and prefilter the input reads against abundant sequences, such as mitochondrial or ribosomal sequences, as defined by iGenomes prebuilt indexes [19]. After filtering, STAR was used for the final mapping prior to fusion detection. STAR supports both splice junction and fusion read detection. STAR aligns reads by finding the Maximal Mappable Prefix (MMP) hits between reads (or read pairs) and the reference genome. Manta was used in combination with STAR to identify fusion transcripts. This workflow is followed by fusion filtering and scoring in BaseSpace RNA-Seq Alignment package based on the following criteria: (1) read counts across fusion and alignment; (2) genomewide realignment of fusion contigs to filter candidates that could be explained by a local alignment elsewhere in the genome; and (3) length of coverage around breakpoints, indicating the presence of stable fusion transcripts. Only high-confidence candidate fusion transcripts passing these filters were selected for downstream analysis [20-22].

\section{Reverse Transcriptase PCR}

Total RNA was extracted from tissues or cell lines using an RNeasy Mini kit (QIAGEN, Aarhus, Denmark). $0.5 \mu \mathrm{g}$ of total RNA were reverse-transcribed into cDNA using a High Capacity cDNA Reverse Transcription Kit (Applied Biosystems, MA, USA), following the manufacturer's instructions. The resultant cDNA served as a template for PCR amplification using the following primers spanning the fusion transcript junctions:

VTI1A sense strand (Exon1) 5' CACCTTCCGGGGTTCCTAAG 3'; VTI1A sense strand (Exon8) 5' CTTCGGGAAACAGATGCTAA 3'; CFAP46 sense strand (Exon30) 5' CAGCAGGAAAATCAGTTCTGG 3'. 
Table 2. Characteristics of tumors on pathology in HCC patients

\begin{tabular}{|c|c|c|c|c|c|}
\hline & $\begin{array}{l}\text { HCC } \\
\text { lesions, } n\end{array}$ & Largest lesion, $\mathrm{cm}$ & $\begin{array}{l}\text { Within } \\
\text { MC }\end{array}$ & $\begin{array}{l}\text { Tumor } \\
\text { differentiation }\end{array}$ & MVI \\
\hline \multicolumn{6}{|c|}{ First phase of study: 6 patients } \\
\hline Patient 1 & 2 & 2.8 & Yes & Moderate & No \\
\hline Patient 2 & 1 & 2.8 & Yes & Well & No \\
\hline Patient 3 & 2 & 2.5 & Yes & Moderate & No \\
\hline Patient 4 & 1 & 1.2 & Yes & Moderate & No \\
\hline Patient 5 & 2 & 1.5 & Yes & Well & No \\
\hline Patient 6 & 1 & 2.1 & Yes & Well & Yes \\
\hline \multicolumn{6}{|c|}{ Second phase of study: additional 13 patients } \\
\hline Patient 7 & 2 & 3 & Yes & Well & No \\
\hline Patient 8 & 1 & 3 & Yes & Moderate & Yes \\
\hline Patient 9 & 1 & 2.8 & Yes & Moderate & No \\
\hline Patient 10 & 1 & 2.5 & Yes & Moderate & No \\
\hline Patient 11 & 3 & 2.1 & Yes & Moderate & No \\
\hline Patient 12 & 2 & 1.9 & Yes & Well & No \\
\hline Patient 13 & 4 & 1.7 & No & Moderate & No \\
\hline Patient 14 & 5 & 3 & No & Moderate & Yes \\
\hline Patient 15 & 1 & 1.5 & Yes & Moderate & No \\
\hline Patient 16 & 4 & 1.7 & No & Well & No \\
\hline Patient 17 & 1 & 2 & Yes & Moderate & No \\
\hline Patient $18^{\mathrm{a}}$ & 1 & 3.6 & Yes & Moderate & Yes \\
\hline Patient 19 & 2 & 4.5 & No & Moderate & Yes \\
\hline
\end{tabular}

HCC, hepatocellular carcinoma; MVI, microvascular invasion; MC, Milan Criteria. ${ }^{\mathrm{a}}$ This patient underwent liver resection rather than liver transplant.

We used Taq DNA polymerase (Invitrogen) for PCR amplification. PCR products were analyzed by agarose gel electrophoresis.

\section{Sanger Sequencing}

Amplified reverse transcriptase PCR (RT-PCR) products were cloned into vector pCR $^{\mathrm{TM}} 4$-TOPO TA Vector and transformed into E. coli according to the manufacturer's instructions (Thermo-Fisher Scientific). Then, the vector was extracted using a Plasmid Mini Kit (QIAGEN) and sequenced via Sanger sequencing according to the manufacturer's instructions.

\section{Quantitative RT-PCR}

Using the same cDNA referred above, we performed quantitative RT-PCR (qRT-PCR). cDNA was amplified using $\mathrm{iQ}^{\mathrm{TM}} \mathrm{SYBR}^{\circledR}$ Green Supermix. The primer sequences for qRT-PCR were:

VTI1A sense strand (Exon 8) 5' CTTCGGGAAACAGATGCTAA 3'; CFAP46 sense strand (Exon 30) 5' CAGCAGGAAAATCAGTTCTGG 3'; VTI1A sense strand (Exon 1) 5' CACCTTCCGGGGTTCCTAAG 3'; VTI1A antisense strand (Exon 2) 5'TCTTTCGCTTCTTCAAGCTG 3'; GAPDH sense strand 5'CAGCCTCAAGATCATCAGCA 3'; GAPDH antisense strand 5'TGTGGTCATGAGTCCTTCCA 3'.

We used GAPDH as an internal control. We measured both wild-type VTI1A transcript levels and VTI1ACFAP46 fusion transcript expression levels using the $2^{-\Delta(\Delta C t)}$ method.

Protein Isolation for Western Blotting and Antibodies Used

HCC and non-HCC liver tissues were collected and homogenized in H-medium ( $210 \mathrm{~mm}$ mannitol, $70 \mathrm{~mm}$ sucrose, 2 mM HEPES, 0.05\% BSA, plus protease and phosphatase inhibitors). VTI1 antibody was obtained from BD Bio Sciences (San Jose, CA, USA). GAPDH antibody was obtained from Santa Cruz Biotechnology (Santa Cruz, CA, USA). Densitometry was performed using the NIH Image J program. 
Table 3. Results of RNA sequencing of HCC and matched non-HCC tissues performed in 6 patients enrolled in the first phase of the study

\begin{tabular}{|c|c|c|c|c|c|c|c|c|c|}
\hline & & Chr 1 & Pos 1 & Strand 1 & Chr 2 & Pos 2 & Strand 2 & Gene 1 & Gene 2 \\
\hline \multirow{3}{*}{ Patient 1} & Non-tumor tissue & 10 & 96541752 & Positive & 10 & 96493052 & Positive & CYP2C19 & CYP2C18 \\
\hline & & 10 & 96827000 & Negative & 10 & 96535204 & Positive & CYP2C8 & CYP2C19 \\
\hline & Tumor tissue & - & - & - & - & - & - & - & - \\
\hline \multirow[t]{7}{*}{ Patient 2} & Non-tumor tissue & 17 & 11984847 & Positive & $\mathrm{X}$ & 72745873 & Negative & MAP2K4 & MAP2K4P1 \\
\hline & & 1 & 155644801 & Negative & 1 & 155753880 & Negative & YY1AP1 & GON4L \\
\hline & & 1 & 155646339 & Negative & 1 & 155753880 & Negative & YY1AP1 & GON4L \\
\hline & Tumor tissue & 10 & 96702075 & Positive & 10 & 96827033 & Negative & CYP2C9 & СYP2C8 \\
\hline & & 10 & 96535273 & Positive & 10 & 96827033 & Negative & CYP2C19 & CYP2C8 \\
\hline & & 16 & 89484692 & Negative & 15 & 93467550 & Positive & ANKRD11 & CHD2 \\
\hline & & 1 & 155631098 & Negative & 1 & 155741008 & Negative & YY1AP1 & GON4L \\
\hline \multirow[t]{2}{*}{ Patient 3} & Non-tumor tissue & 10 & 96826989 & Negative & 10 & 96535226 & Positive & CYP2C8 & CYP2C19 \\
\hline & Tumor tissue & - & - & - & - & - & - & - & - \\
\hline \multirow[t]{4}{*}{ Patient 4} & Non-tumor tissue & 10 & 96702075 & Positive & 10 & 96827033 & Negative & CYP2C9 & CYP2C8 \\
\hline & & 10 & 96826988 & Negative & 10 & 96535228 & Positive & CYP2C8 & CYP2C19 \\
\hline & & 10 & 96541752 & Positive & 10 & 96493052 & Positive & CYP2C19 & CYP2C18 \\
\hline & Tumor tissue & 10 & 96826985 & Negative & 10 & 96535225 & Positive & CYP2C8 & CYP2C19 \\
\hline \multirow[t]{5}{*}{ Patient 5} & Non-tumor tissue & 6 & 44218178 & Positive & 15 & 58984703 & Negative & HSP90AB1 & HSP90AB4P \\
\hline & & 10 & 96702073 & Positive & 10 & 96827034 & Negative & СYP2C9 & CYP2C8 \\
\hline & & 10 & 96702073 & Positive & 10 & 96535226 & Positive & СYP2C9 & CYP2C19 \\
\hline & & 10 & 96702073 & Positive & 10 & 96447961 & Positive & CYP2C9 & CYP2C18 \\
\hline & Tumor tissue & - & - & - & - & - & - & - & - \\
\hline \multirow[t]{4}{*}{ Patient 6} & Non-tumor tissue & 10 & 96702075 & Positive & 10 & 96827033 & Negative & CYP2C9 & CYP2C8 \\
\hline & & 22 & 36696211 & Negative & 19 & 50774702 & Positive & MYH9 & MYH14 \\
\hline & Tumor tissue & 10 & 114428755 & Positive & 10 & 134691514 & Positive & VTI1A & TTC40 \\
\hline & & 10 & 96541752 & Positive & 10 & 96493052 & Positive & CYP2C19 & CYP2C18 \\
\hline
\end{tabular}

Chr, chromosome; Pos, position; CYP2C, cytochrome P450 2C; MAPK, mitogen-activated protein kinase; YY1AP1, YY1-associated protein 1; GON4L, GON4-like protein; MYH, myosin heavy chain; ANKRD11, ankyrin repeat domain 11; CHD2, chromodomain-helicaseDNA-binding protein 2; HSP90, heat shock protein 90; TTC40, tetratricopeptide repeat domain 40.

\section{Results}

\section{Clinical Data}

Clinical information on the 6 patients enrolled in the first phase of the study (Fig. 1) as well as the additional 13 patients enrolled in the second phase of the study (Fig. 1) is summarized in Table 1 and 2. Patients with a diagnosis of HCC who underwent liver transplantation at the Johns Hopkins Hospital in 2015 and 2016 (with the exception of 1 patient who had liver resection), were identified under our approved IRB protocol, and consent was obtained prior to surgery. Patients were between 48 and 68 years of age. Biological MELD scores ranged from 6 to 15. Regarding etiology of underlying liver disease, 14 out of $19(73.7 \%)$ patients had HCV cirrhosis (2 patients had concomitant HIV infection, 1 had concomitant hepatitis B infection, and 1 had concomitant alcoholic liver disease); 3 patients had NASH or cryptogenic cirrhosis, 1 patient had HBV cirrhosis, and 1 patient had alcoholic cirrhosis. Pretransplant 


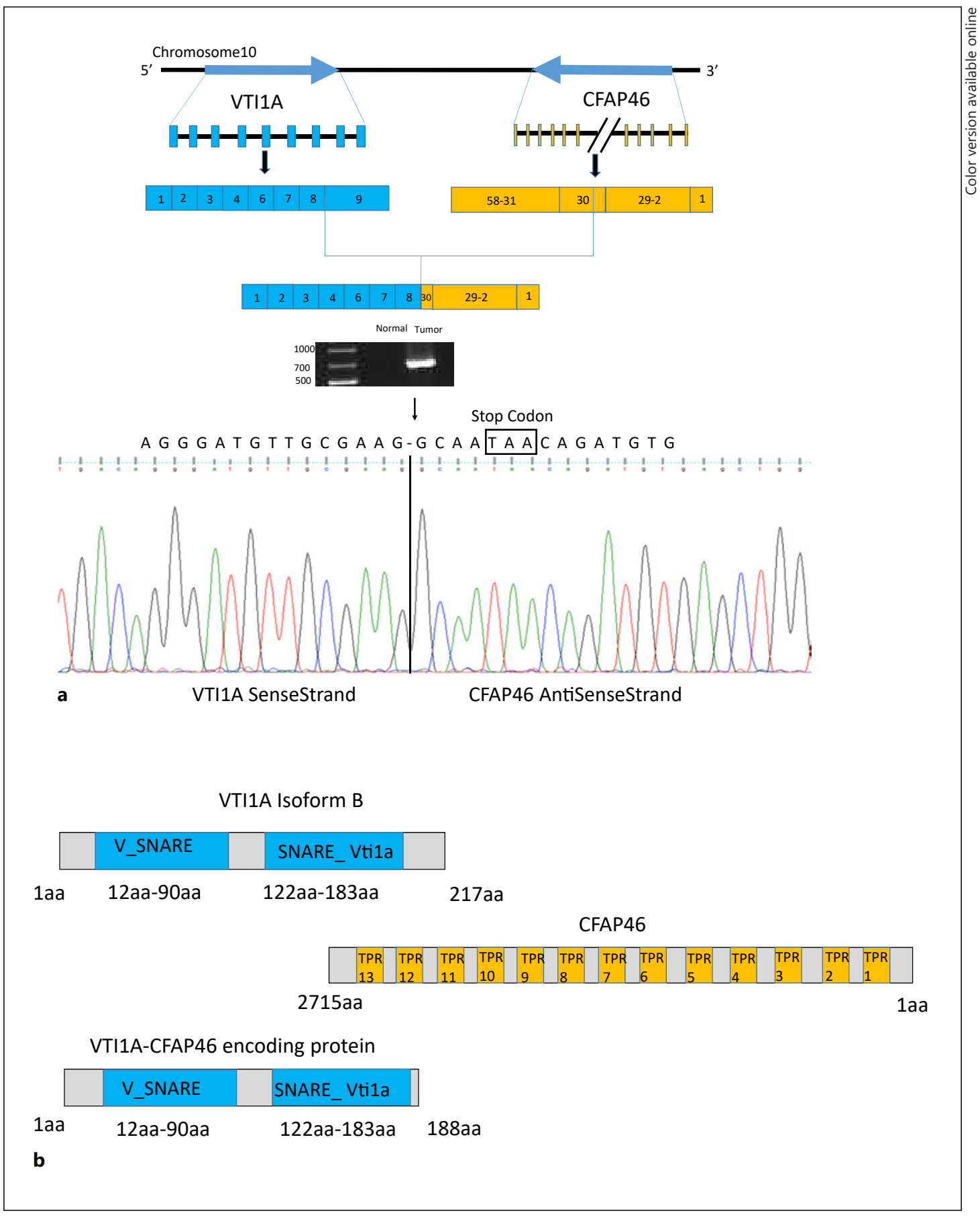

Fig. 2. Validation of the VTI1A-CFAP46 fusion transcript. a VTI1A and CFAP46 are both located in chromosome 10: VTI1A is located at position 112446988-112947204, while CFAP46 is located at position 132808392-132942585 (NCBI Reference GRCh38.p7 Primary Assembly). Transcription of these genes occurs in opposite directions; as a result, the fusion transcript consists of the sense strand of VTI1A exons 1-4 and 6-8 fused to the antisense strand of CFAP46 exons 1-30. RT-PCRs of paired tumor/nonmalignant cases using primers spanning each fusion junction confirmed that bands corresponding to the fusion transcript were present only in tumor. Sanger sequencing confirmed the fusion junction sequences of VTI1A exon 8 and CFAP46 exon 30. b The protein encoded by the fusion transcript has lost 29 amino acids and changed 1 amino acid $(\mathrm{I} \rightarrow \mathrm{Q})$ at the $\mathrm{C}$-terminus of VTI1A due to a stop codon caused by the fusion. 
Gastro

Intestinal

Tumors
Gastrointest Tumors 2019;6:11-27

\begin{tabular}{l|l}
\hline DOI: 10.1159/000496795 & ( 2019 S. Karger AG, Basel
\end{tabular}

www.karger.com/gat

Tsuge et al.: Fusion Transcripts in Hepatocellular Carcinoma

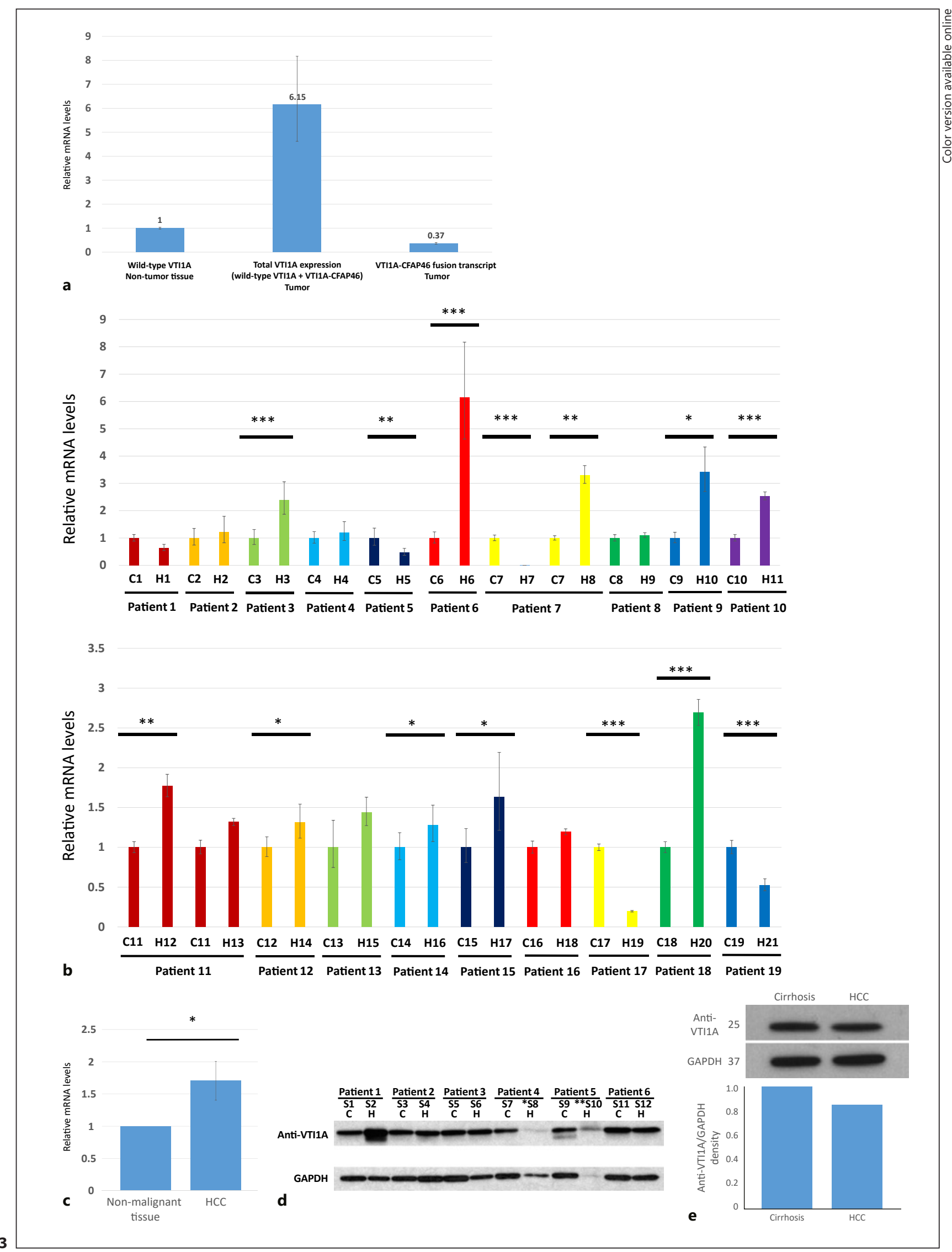

KARGER 
AFP (alpha fetoprotein) levels ranged from 1.8 to 179.3. The duration of posttransplant follow-up was between 125 and 532 days. During the follow-up period, 1 patient required retransplantation and subsequently died due to complications from hepatic artery thrombosis and frequent infections. Two (10.5\%) patients had HCC recurrence following surgery that was diagnosed during the follow-up period.

\section{Pathology}

Characteristics of tumors on explant pathology were reviewed by an expert pathologist and are summarized in Table 2. All patients had between 1 and 5 HCC lesions. 4 of 19 (21\%) were discovered to be outside of the Milan Criteria on explant pathology. Five (26\%) patients had well-differentiated tumors on explant histopathological exam, while the remainder had moderately differentiated HCCs. Overall, 5 (26.3\%) of 19 patients had microvascular invasion on explant.

\section{Targeted RNA-seq of 6 HCC and Paired Non-HCC Liver Tissues with Advanced Fibrosis or}

Cirrhosis, and Discovery of Fusion Transcripts

Six HCC samples and their matched nonmalignant tissues were first analyzed by targeted RNA-seq, as described above. The mean number of reads was 4,910,333 \pm 4801945 (SD), and the length of each read was 76 nucleotides. The mean ratio of aligned reads was $97 \%$; among aligned reads, $69.6 \%$ were matched to coding regions, $21.8 \%$ to UTR regions, $5.8 \%$ to intron regions, and $2.8 \%$ to nontargeted regions. We analyzed paired-end sequencing reads using Manta according to the strategy mentioned above, which identified various translocations or rearrangements in HCC and cirrhotic tissue.

Results of analysis of RNA-seq data are shown in Table 3. In HCC tissues, various rearrangements were noted that were paralogs likely false positive. We evaluated one of the rearrangements involving chromosome 10 which occurred in an HCC, between VTI1A and TTC40, and will be discussed.

\section{Validation of the VTI1A-CFAP46 Fusion Transcript}

We chose to study VTI1A-CFAP46 fusion in HCC, based on the reported fusions of these genes in the literature in other types of cancers $[12,17]$. To validate our initial finding of the VTI1A-CFAP46 fusion transcript, we performed RT-PCR using primer pairs spanning the junctions of this fusion transcript (Fig. 2a). We were able to detect a band of the correct

Fig. 3. a Expression of wild-type VTI1A and the VTI1A-CFAP46 fusion transcript, measured by qRT-PCR in sample 12. In patient 6, total VTI1A expression was 6-fold upregulated in tumor relative to nonmalignant tissue; but, expression of the fusion transcript was 16-fold lower than wild-type VTI1A in tumor tissue. In this graph, the $y$ axis illustrates relative expression of mRNA, with the expression of mRNA in sample 11, nontumor samples being 1. b Expression of wild-type VTI1A RNA in 19 studied patients (21 HCC and 19 paired nonmalignant specimens: total of 40 specimens). Among 21 HCC samples studied, VTI1A was upregulated in 10, downregulated in 4, and unchanged in the other 7 samples, compared to their matched non-HCC tissue. c Expression in all HCC samples compared to all non-HCCs. In this graph, the $y$ axis illustrates relative expression of mRNA, with the expression of mRNA in each matched nontumor samples being 1 . Significance was calculated using the paired $t$ test, with $p<0.05$ considered statistically significant. $*<<0.05, * * p<0.01$, $* * * p<0.005$. C, cirrhosis; H, HCC. d Wild-type VTI1A protein expression in HCC and matched cirrhotic tissues of 12 patients. Western blot analysis was performed using antisera against VTI1A and GAPDH. S, sample; C, cirrhosis; H, HCC. * Anti-VTI1A and GAPDH quantity was low in sample 8 due to lack of adequate sample. ** Proteins were degraded in sample 10, precluding measurement of VTI1A and GAPDH. e The Western blot illustrating protein levels of anti-VTI1A in reported patient with VTI1A-CFAP46 mutation in HCC and nonHCC tissues. 
Gastro

Intestinal

Tumors
Gastrointest Tumors 2019;6:11-27

DOI: $10.1159 / 000496795$

(c) 2019 S. Karger AG, Basel

www.karger.com/gat

Tsuge et al.: Fusion Transcripts in Hepatocellular Carcinoma
Study of origin

VTI1A

CFAP46

\section{| |||||||||||||||||||||||||||||||||||||||||||||||||||||||||||||||||||||||||||||||||||||||}

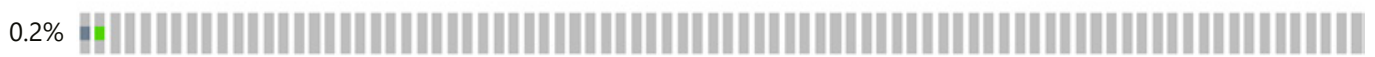

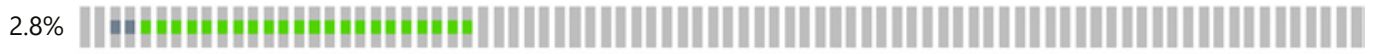

Genetic alteration

" Missense mutation (unknown significance) || No alterations || Truncating mutation (unknown significance)

Study of origin

\Hepatocellular carcinomas (Inserm, Nat Genet 2015) \Liver hepatocellular carcinoma (AMC, Hepatology 2014)

a

| Liver hepatocellular carcinoma (RIKEN, Nat Genet 2012) 【 Liver hepatocellular carcinoma (TCGA, provisional)
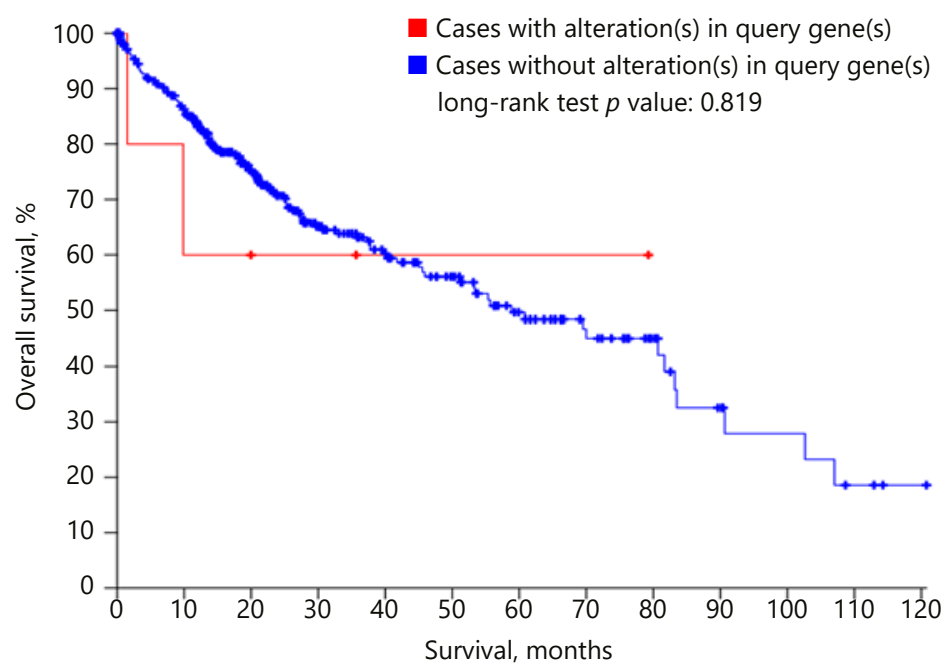

$\begin{array}{llll} & \begin{array}{l}\text { Number of } \\ \text { cases, total }\end{array} & \begin{array}{l}\text { Number of } \\ \text { cases, deceased }\end{array} & \begin{array}{l}\text { Median months } \\ \text { survival }\end{array} \\ \text { Cases with alteration(s) in query gene(s) } & 6 & 2 & \text { NA } \\ \text { Cases without alteration(s) in query gene(s) } & 359 & 125 & 58.84\end{array}$

b

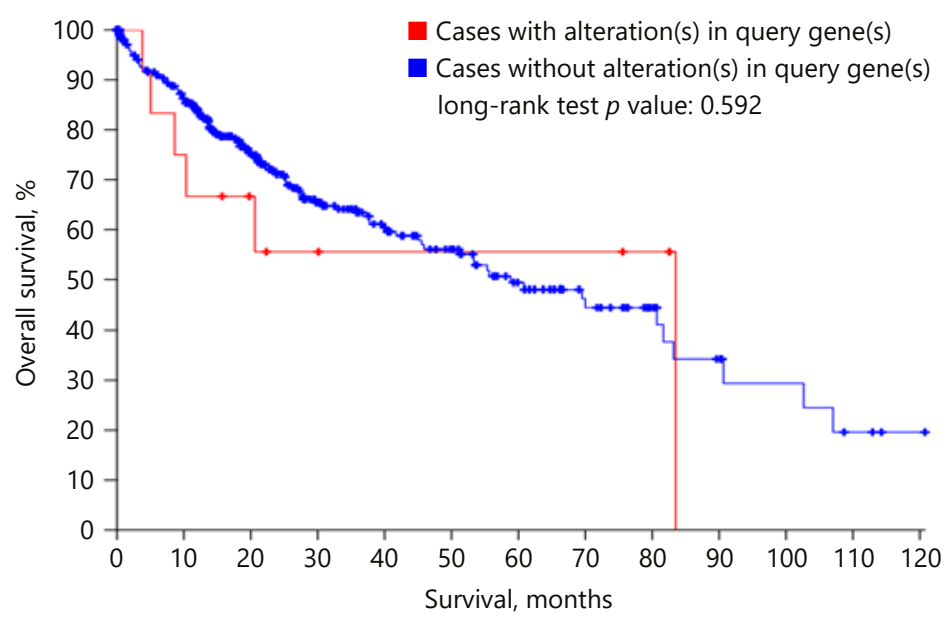

$\begin{array}{llll} & \begin{array}{l}\text { Number of } \\ \text { cases, total }\end{array} & \begin{array}{l}\text { Number of } \\ \text { cases, deceased }\end{array} & \begin{array}{l}\text { Median months } \\ \text { survival }\end{array} \\ \text { Cases with alteration(s) in query gene(s) } & 13 & 6 & 83.51 \\ \text { Cases without alteration(s) in query gene(s) } & 352 & 121 & 58.84\end{array}$


predicted size, representing the fusion transcript, in one primary HCC tissue (patient 6, sample 12). Next, we performed Sanger sequencing to confirm the breakpoints of VTI1A and CFAP46. Sequencing results confirmed that this fusion transcript arose from the sense strand of VTI1A exons 1-4 and 6-8 fused to the antisense strand of CFAP46 exons 1-30 (Fig. 2a). We also confirmed that the VTI1A genomic DNA was not similar to any other genomic region on chromosome 10 by BLAST. VTI1A and CFAP 46 are both located on chromosome 10; therefore, we concluded that this transcript was transcribed from a genomic DNA VTI1A-CFAP46 translocation event. VTI1A isoform B has two domains, which are called V_SNARE and SNARE_ Vti1a. CFAP46 has 13 domains, which are known as tetratricopeptide repeats (TPR) 1-13 (Fig. 2b). Finally, we were unable to detect this VTI1A-CFAP46 fusion transcript in either of two HCC-derived cell lines (97L, 97H) using RT-PCR.

\section{Measuring Expression of the VTI1A-CFAP46 Fusion Transcript and the Wild-Type VTI1A}

Transcript

To measure expression levels of the VTI1A-CFAP46 fusion transcript in HCC, we performed qRT-PCR. We also measured the expression of wild-type VTI1A, using paired nonmalignant tissues as controls. This comparison revealed that the expression of the VTI1A-CFAP46 fusion transcript was 16-fold lower than the expression of wild-type VTI1A in the same tumor (Fig. 3a). Additionally, we measured the expression of wild-type VTI1A, which showed that in 10/21 HCC samples analyzed, wild-type VTI1A was upregulated (Fig. 3b, c).

\section{Measurement of VTI1A Protein Expression in HCC and Non-HCC Tissues}

To evaluate potential downstream modulation in protein expression, Western blotting was performed in the original HCC sample in which the VTI1A-CFAP46 fusion transcript was detected and compared with paired non-HCC tissue. The wild-type VTI1A protein was detected at $29 \mathrm{kDa}$ in both samples and was similar in expression level between HCC and non-HCC cirrhotic tissues (Fig. 3e). There was no evidence of a mutated protein product resulting from VTI1A-CFAP46 fusion, at least on the Western blot. Western blotting was also performed on the remaining 6 paired HCC and non-HCC samples for anti-VTI1A; this experiment revealed no differences between normal and tumor tissues (Fig. 3d).

\section{VTI1A and CFAP46 Mutations from cBioPortal}

We then performed a search in the cBioPortal database [23-27] to look for any similar mutations reported in the literature for two genes of interest in patients with HCC: VTI1A and CFAP46. We did not find any reported fusions between VTI1A and CFAP46 in HCC. However, there were reports of other somatic mutations in CFAP46 and VTI1A genes on chromosome 10 (Table 4). Overall, both genes were altered in $26(3 \%)$ of 872 sequenced patients with HCC. VTI1A was altered in $2(0.2 \%)$ of 872 sequenced cases, and CFAP46 was altered in $24(2.8 \%)$ of 872 sequenced cases (Fig. 4a, Table 4). In terms of overall survival, there was no difference between patients who had VTI1A mutation when compared to patients with no VTI1 mutation in the TCGA database (log-rank test $p=0.819$ ) (Fig. $4 \mathrm{~b}$ ). It is important to note that the number of patients with mutation was small. Similarly, the overall survival was not different between patients with or without CFAP46 mutation (log-rank test $p=0.592$ ) (Fig. 4c) [23-27].

Fig. 4. a Frequency of the somatic mutations for CFAP46 and VTI1A in cBioportal [23-27]. Overall, both genes were altered in 26 (3\%) of 872 sequenced patients with HCC [23-27]. b Comparison of overall survival for patients with or without VTI1A in TCGA and cBioportal database (cBioPortal.org). c Comparison of overall survival for patients with or without CFAP46 in TCGA and cBioportal database (cBioPortal.org). 
Table 4. Reported VTI1A and CFAP46 mutations in cBioPortal [23-27]

\begin{tabular}{|c|c|c|c|c|c|}
\hline Study & $\begin{array}{l}\text { Mutation } \\
\text { type }\end{array}$ & $\begin{array}{l}\text { Copy } \\
\text { number }\end{array}$ & $\begin{array}{l}\text { Protein } \\
\text { change }\end{array}$ & $\begin{array}{l}\text { Allele } \\
\text { frequency }(\mathrm{T})\end{array}$ & Chromosome \\
\hline \multicolumn{6}{|l|}{ A VTI1A mutations } \\
\hline TCGA, provisional & Missense & ShallowDel & H117L & 0.15 & 10 \\
\hline TCGA, provisional & Missense & Gain & V41L & 0.28 & 10 \\
\hline TCGA, provisional & Missense & Gain & $\mathrm{E} 42 \mathrm{D}$ & 0.24 & 10 \\
\hline TCGA, provisional & Non-sense & Gain & $\mathrm{K} 43^{*}$ & 0.25 & 10 \\
\hline TCGA, provisional & Frameshift deletion & Gain & V41Nfs*32 & 0.18 & 10 \\
\hline \multicolumn{6}{|c|}{ B $\quad$ CFAP46 mutations } \\
\hline Inserm & Missense & - & A1606 & - & 10 \\
\hline Inserm & Nonsense & - & E192* & - & 10 \\
\hline Inserm & Missense & - & K502E & - & 10 \\
\hline Inserm & Missense & - & V1568L & - & 10 \\
\hline Inserm & Missense & - & G2198R & - & 10 \\
\hline Inserm & Missense & - & $\mathrm{T} 1805 \mathrm{~N}$ & - & 10 \\
\hline Inserm & Missense & - & G1318S & - & 10 \\
\hline Inserm & Missense & - & $\mathrm{A} 1040 \mathrm{~T}$ & - & 10 \\
\hline Inserm & Missense & - & R598Q & - & 10 \\
\hline Inserm & Missense & - & $\mathrm{A} 18 \mathrm{~T}$ & - & 10 \\
\hline AMC & Missense & - & I1248V & 0.25 & 10 \\
\hline $\mathrm{AMC}$ & Missense & - & G1571W & 0.17 & 10 \\
\hline AMC & Missense & - & A18S & 0.22 & 10 \\
\hline TCGA, provisional & Missense & Diploid & V366F & 0.35 & 10 \\
\hline TCGA, provisional & Missense & Diploid & D1088N & 0.49 & 10 \\
\hline TCGA, provisional & Missense & Diploid & M1213V & 0.10 & 10 \\
\hline TCGA, provisional & Frameshift insertion & ShallowDel & R756Afs*17 & 0.08 & 10 \\
\hline TCGA, provisional & Missense & ShallowDel & L181I & 0.68 & 10 \\
\hline TCGA, provisional & Missense & Gain & $\mathrm{C} 2125 \mathrm{~S}$ & 0.4 & 10 \\
\hline TCGA, provisional & Missense & Gain & K1053M & 0.49 & 10 \\
\hline TCGA, provisional & Missense & Diploid & D648Y & 0.23 & 10 \\
\hline TCGA, provisional & Missense & ShallowDel & P2421S & 0.08 & 10 \\
\hline TCGA, provisional & Missense & Diploid & L1006Q & 0.28 & 10 \\
\hline TCGA, provisional & Missense & Diploid & V587A & 0.05 & 10 \\
\hline TCGA, provisional & Missense & Diploid & $\mathrm{I} 1772 \mathrm{~T}$ & 0.05 & 10 \\
\hline TCGA, provisional & Missense & Diploid & L1298Q & 0.54 & 10 \\
\hline TCGA, provisional & Missense & ShallowDel & E1673G & 0.05 & 10 \\
\hline
\end{tabular}

\section{Discussion}

Newer genome sequencing technologies have now enabled us to explore the genomic profile of HCC more deeply to better identify its complex molecular pathophysiology. Several studies applying deep sequencing have provided information on the mutational profile of HCC [28-30]. These studies have revealed involvement of various critical signaling pathways. The most common mutations described have occurred in the TERT promoter, $\mathrm{Wnt} / \beta$-Catenin pathway genes, $\mathrm{p} 53$, chromatin remodeling genes, RAS/MAPK signaling components, and oxidative stress genes [31]. In addition, HCC mutations have been implicated in crucial cellular processes such as homeostasis, proliferation, and cellcycle control. Hepatocellular tumors have been classified into two main groups based on their mutational profiles: proliferative and nonproliferative, each representing approximately $50 \%$ of patients. Overall, the proliferative subclass is defined by classic activation of RAS, mTOR and/or IGF signaling and is associated with a poor outcome relative to the 


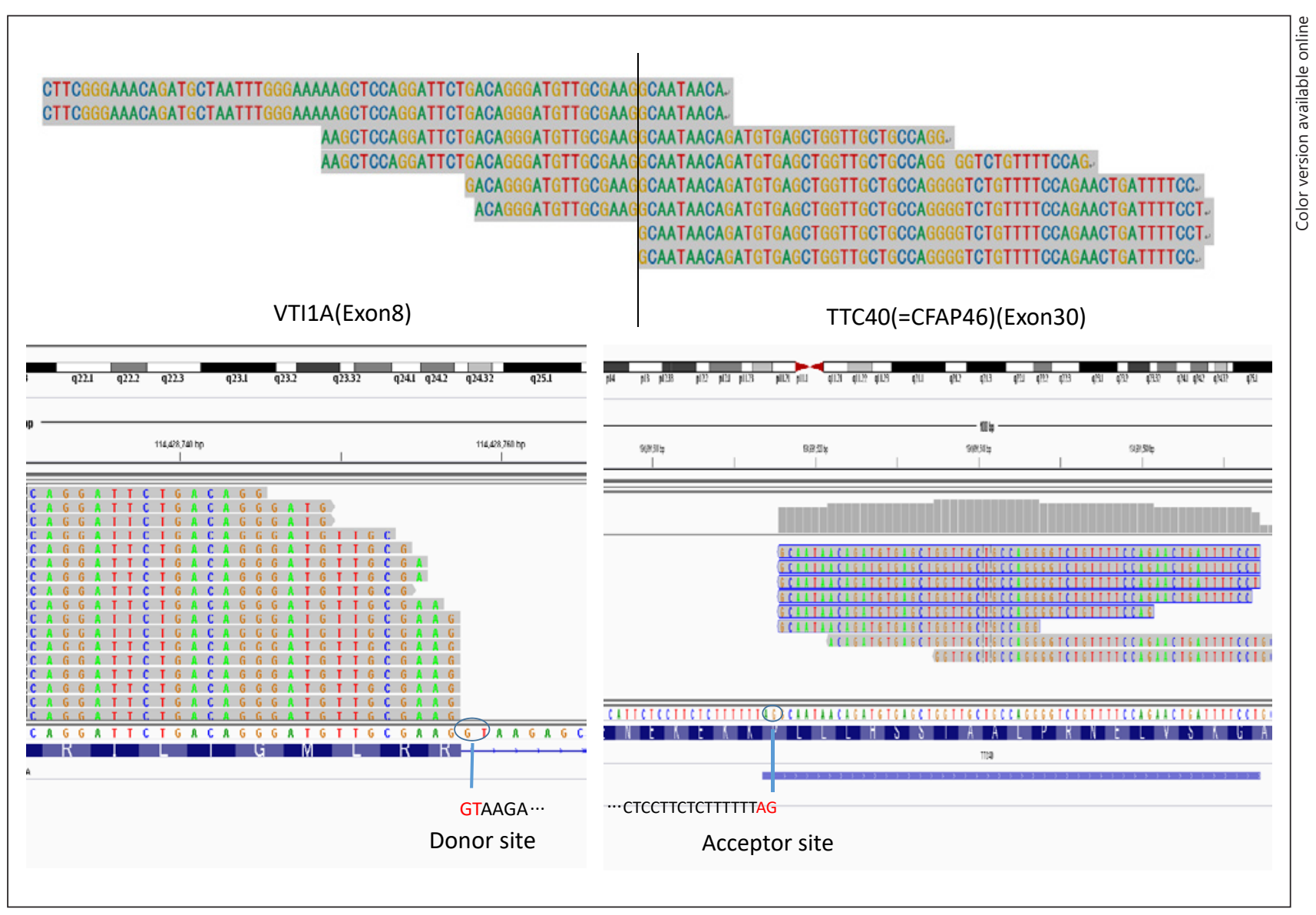

Fig. 5. Readmap of the VTI1A-CFAP46 fusion transcript. The breakpoint attaches the $3^{\prime}$ end of VTI1A exon 8 to the middle of CFAP46 exon 30. In CFAP46 exon 30, there is a polypyrimidine tract followed immediately by a splice acceptor site. As a result, cryptic splicing occurs.

nonproliferative subtype [28, 32]. Fusion transcripts, however, have not to our knowledge been extensively studied in HCC.

There is growing evidence that fusion transcripts are critical events in the development and/or progression of various human cancers. The Philadelphia chromosome is the prototype fusion gene reported in patients with CML, resulting from a translocation between chromosomes 9 and 22 [33]. Following the development of newer high-throughput sequencing technologies, fusion transcripts have now been discovered in various solid cancers, including colon, lung, breast, and prostate tumors [7, 34-36]. Fusion transcripts have been described in fibrolamellar HCC (FLH) [37]. FLH is a rare form of liver cancer that is seen in children and young adults. In contrast to HCC, FLH occurs in noncirrhotic liver tissue and has a better prognosis. A fusion chimera with deletion of chromosome 19 was discovered in FLC, namely, DNAJB1-PRKACA [38]. This candidate transcript and its predicted protein is the result of fusion of exon 1 from DNAJB1, a member of the heat shock protein 40 family, with exons 2-10 from PRKACA which encodes the CAMP-dependent protein kinase (PKA) catalytic unit alpha, leading to full retained catalytic activity of wild-type PKA [37]. More recently, fusion of genes and associated downstream protein, mannosidase a class 2A member 1-FER tyrosine kinase gene (MAN2A1-FER) was reported in multiple HCC cell lines and 14\% of human HCC specimens [39]. In mice, MAN2A1-FER caused rapid liver cancer that was associated with PTEN mutation [39]. Druggable fusions of fibroblast 
growth factor receptor 2 (FGFR2) have been discovered in patients with cholangiocarcinoma. Studies evaluating small molecular inhibitors targeting FGFR2 are under investigation [40].

It is now apparent that fusion transcripts are more common in solid tumors than was previously believed. Fusion transcripts offer several advantages as potential clinical tools. For example, they can be used in diagnosis, screening, and monitoring of disease recurrence $[36,41,42]$. Additional significance is conferred by the possibility of discovering downstream fusion proteins resulting from chimeric RNAs, which may exert cancer-promoting pathogenic effects. One evident example concerns imatinib, which was discovered in 2001 and targets the BCR-ABL fusion protein in patients with CML, with substantial therapeutic benefit [41].

In the current work, we explored fusion transcripts in HCC and discovered a novel transcript of particular note: VTI1A-CFAP46. Although the VTI1A-CFAP46 fusion transcript was detected only in one HCC sample, wild-type VTI1A RNA was upregulated in many of the HCC specimens. VTI1A wild-type protein, however, was not upregulated in HCC. This apparent discrepancy between RNA and protein findings could be due to differences in posttranscriptional processing or protein stability. We did not detect any mutant or truncated VTI1A-CFAP46 protein using a VTI1A antibody. At the present time, the precise role of this VTI1A-CFAP46 fusion transcript is unclear. VTI1A is known to be required for maturation of the autophagosome and mediates autophagy flux. Autophagy has both positive and negative functions in cancer. In normal tissues or cells, it is essential for the turnover of cellular components and degrades damaged organelles and proteins. In this setting, it relieves cell stress and genomic damage and suppresses tumorigenesis. In the liver, decreased autophagy can result in tumorigenesis [16]. This may occur because the liver is more active metabolically compared to other organs. In contrast, autophagy promotes tumor growth and angiogenesis in pancreatic and gastric cancers $[43,44]$. Therefore, we believe that future studies are required to better define the relationship between autophagy and VTI1A or other SNARE proteins in advanced fibrosis, cirrhosis, and HCC that will help illuminate the pathogenesis of HCC, the link between fibrosis and HCC, and development of future hepatocellular cancer therapies.

Fusion transcripts involving VTI1A have been described in colorectal cancers. In one study, VTI1A was fused with TCF7L2 in 3\% of colorectal cancers. TCF7L2 encodes TCF4, which cooperates with $\beta$-catenin in colorectal carcinogenesis, but the fusion protein lacked the TCF4 $\beta$-catenin-binding domain [12]. Functions of the CFAP46 gene are not known and open to question. The CFAP46 protein contains a TPR that is a structural motif, consisting of a degenerate 34-amino acid sequence motif that has been identified in a wide variety of proteins. The TPR domain is found in tandem arrays of 3-16 motifs, which form scaffolds to mediate protein-protein interactions and often the assembly of multiprotein complexes. The consequences of CFAP46 dysregulation in cancer remain an unanswered question deserving further investigation [17]. In one study, the 5'-TTC40 gene (the old name for CFAP46) was frequently hypermethylated and associated with loss of mRNA expression in nasopharyngeal cancer [17]. It was therefore proposed that TTC40 (the old name for CFAP46) might play a role in the development of this cancer [17].

Our findings in the current study establish the importance of further fusion transcript research in HCC. Several critical questions remain, such as: (1) How frequent are fusion transcripts in HCC? (2) What causes fusion transcripts to occur in HCC? and (3) What is the significance of these types of genomic alteration in HCC? In the future, the frequency of these alterations can be determined by performing RNA-seq in much larger cohorts of HCC and paired nonmalignant tissues, since the occurrence rates of fusion transcripts may be very low [45]. Recently, chromothripsis and chromoplexy have been discovered as causes of fusion transcripts $[46,47]$. Retrotransposition is also well known to cause fusion genes or insertions. This fusion transcript may also have been generated by cryptic splicing. In this context, the antisense strand of CFAP46 exon 30 has a splice acceptor site and polypyrimidine tract; moreover, cryptic splicing would explain why the breakpoint matched the middle sequence of the CFAP46 exon 
(Fig. 5). Cryptic splicing is known to cause certain diseases, such as Hutchinson-Gilford progeria [48]. Although speculative, we hypothesize that cryptic splicing may also be involved in the pathogenesis of HCC but requires further studies.

Herein, we have described a novel fusion transcript, VTI1A-CFAP46, whose function merits further investigation in future studies. As discussed above, the link between this alteration and autophagy deserves further exploration. It is well known that autophagy is involved in HCC as well as benign liver disease. Our study has also revealed several fusions and rearrangement transcripts in HCC and cirrhosis that warrant further investigation. It is well known that advanced liver fibrosis and cirrhosis are strongly associated with HCC [48]. Although several potential mechanisms associating liver fibrosis with hepatocarcinogenesis have been described $[49,50]$, the precise mechanism underlying this connection has not yet been firmly elucidated [48]. Studying fusion transcripts in this context may help us to better understand the link between fibrosis and HCC.

\section{Acknowledgements}

We wish to acknowledge the expert assistance of Lisa Watson and Allison Yunghans at Illumina in RNA sequencing and data analysis.

\section{Statement of Ethics}

These studies were performed in compliance with approved Johns Hopkins human subjects IRB Protocol NA_00004336.

\section{Disclosure Statement}

Robert Anders received research fund from the Fibrolamellar Cancer Foundation. All other authors have no conflicts of interest.

\section{Funding Sources}

NIH grants CA190040, CA211457, and the Johns Hopkins Transplant Hepatology Research Fund \#80023797. S.J.M. is an American Cancer Society Clinical Research Professor and the Harry and Betty Myerberg/Thomas R. Hendrix Professor of Gastroenterology.

\section{Author Contributions}

S.T.: study concept and design, acquisition of data, analysis and interpretation of data, statistical analysis, drafting of the manuscript; B.S.: study concept and design, acquisition of data, analysis and interpretation of data, statistical analysis, drafting of the manuscript; Y.C.: study concept and design, acquisition of data, analysis and interpretation of data, statistical analysis; Z.W.: acquisition of data, analysis and interpretation of data, statistical analysis; A.K.: acquisition of data, drafting of the manuscript; H.L.: acquisition of data; J.M.A.: analysis and interpretation of data, statistical analysis; M.D.Y.: acquisition of data; J.P.H.: acquisition of data, funding; F.M.S.: study concept and design, analysis and interpretation of data; C.V.-M.: acquisition of data, drafting of the manuscript, analysis and interpretation of data, statistical analysis; F.S.: acquisition of data, analysis and interpretation of data; B.P.: acquisition of data; A.M.C.: acquisition of data; Q.Z.: acquisition of data; R.A.: acquisition of data, analysis and interpretation of data; A.G.: study concept and design, acquisition of data, analysis and interpretation of data, drafting of the manuscript, critical revision of the manuscript for important intellectual content, study supervision, funding; S.J.M.: study concept and design, acquisition of data, drafting of the manuscript, analysis and interpretation of data, statistical analysis, critical revision of the manuscript for important intellectual content, study supervision, funding. 


\section{References}

1 Park JW, Chen M, Colombo M, Roberts LR, Schwartz M, Chen PJ, et al. Global patterns of hepatocellular carcinoma management from diagnosis to death: the BRIDGE Study. Liver Int. 2015 Sep;35(9):2155-66.

2 Bosetti C, Turati F, La Vecchia C. Hepatocellular carcinoma epidemiology. Best Pract Res Clin Gastroenterol. 2014 Oct;28(5):753-70.

3 Chuang SC, La Vecchia C, Boffetta P. Liver cancer: descriptive epidemiology and risk factors other than HBV and HCV infection. Cancer Lett. 2009 Dec;286(1):9-14.

4 Yang JD, Roberts LR. Hepatocellular carcinoma: A global view. Nat Rev Gastroenterol Hepatol. 2010 Aug; 7(8): 448-58.

5 Zucman-Rossi J, Villanueva A, Nault JC, Llovet JM. Genetic Landscape and Biomarkers of Hepatocellular Carcinoma. Gastroenterology 2015;149:1226-1239 e1224.

6 Kang ZJ, Liu YF, Xu LZ, Long ZJ, Huang D, Yang Y, et al. The Philadelphia chromosome in leukemogenesis. Chin J Cancer. 2016 May;35(1):48.

7 Rossi A, Maione P, Sacco PC, Sgambato A, Casaluce F, Ferrara ML, et al. ALK inhibitors and advanced non-small cell lung cancer (review) [review]. Int J Oncol. 2014 Aug;45(2):499-508.

$8 \mathrm{Yu}$ J, Yu J, Mani RS, Cao Q, Brenner CJ, Cao X, et al. An integrated network of androgen receptor, polycomb, and TMPRSS2-ERG gene fusions in prostate cancer progression. Cancer Cell. 2010 May;17(5):443-54.

9 Kas K, Voz ML, Röijer E, Aström AK, Meyen E, Stenman G, et al. Promoter swapping between the genes for a novel zinc finger protein and beta-catenin in pleiomorphic adenomas with $\mathrm{t}(3 ; 8)$ (p21;q12) translocations. Nat Genet. 1997 Feb;15(2):170-4.

10 Soda M, Choi YL, Enomoto M, Takada S, Yamashita Y, Ishikawa S, et al. Identification of the transforming EML4-ALK fusion gene in non-small-cell lung cancer. Nature. 2007 Aug;448(7153):561-6.

11 Laszlo A, Thotala D, Hallahan DE. Membrane phospholipids, EML4-ALK, and Hsp90 as novel targets in lung cancer treatment. Cancer J. 2013 May-Jun;19(3):238-46.

12 Bass AJ, Lawrence MS, Brace LE, Ramos AH, Drier Y, Cibulskis K, et al. Genomic sequencing of colorectal adenocarcinomas identifies a recurrent VTI1A-TCF7L2 fusion. Nat Genet. 2011 Sep;43(10):964-8.

13 Meng J, Wang J. Role of SNARE proteins in tumourigenesis and their potential as targets for novel anti-cancer therapeutics. Biochim Biophys Acta. 2015 Aug; 1856(1):1-12.

14 Lu Y, Zhang Z, Sun D, Sweeney ST, Gao FB. Syntaxin 13, a genetic modifier of mutant CHMP2B in frontotemporal dementia, is required for autophagosome maturation. Mol Cell. 2013 Oct;52(2):264-71.

15 Fu DZ, Cheng Y, He H, Liu HY, Liu YF. Recombinant human PDCD5 exhibits an antitumor role in hepatocellular carcinoma cells via clathrin-dependent endocytosis. Mol Med Rep. 2015 Dec;12(6):8135-40.

16 Takamura A, Komatsu M, Hara T, Sakamoto A, Kishi C, Waguri S, et al. Autophagy-deficient mice develop multiple liver tumors. Genes Dev. 2011 Apr;25(8):795-800.

17 Ayadi W, Allaya N, Frikha H, Trigui E, Khabir A, Ghorbel A, et al. Identification of a novel methylated gene in nasopharyngeal carcinoma: TTC40. BioMed Res Int. 2014;2014:691742.

18 Li Y, Tang ZY, Ye SL, Liu YK, Chen J, Xue Q, et al. Establishment of cell clones with different metastatic potential from the metastatic hepatocellular carcinoma cell line MHCC97. World J Gastroenterol. 2001 Oct; 7(5):630-6.

19 Langmead B, Trapnell C, Pop M, Salzberg SL. Ultrafast and memory-efficient alignment of short DNA sequences to the human genome. Genome Biol. 2009;10(3):R25.

20 Trapnell C, Pachter L, Salzberg SL. TopHat: discovering splice junctions with RNA-Seq. Bioinformatics. 2009 May;25(9):1105-11.

21 Dobin A, Davis CA, Schlesinger F, Drenkow J, Zaleski C, Jha S, et al. STAR: ultrafast universal RNA-seq aligner. Bioinformatics. 2013 Jan;29(1):15-21.

22 Chen X, Schulz-Trieglaff O, Shaw R, Barnes B, Schlesinger F, Källberg M, et al. Manta: rapid detection of structural variants and indels for germline and cancer sequencing applications. Bioinformatics. 2016 Apr;32(8): 1220-2.

23 Cerami E, Gao J, Dogrusoz U, Gross BE, Sumer SO, Aksoy BA, et al. The cBio cancer genomics portal: an open platform for exploring multidimensional cancer genomics data. Cancer Discov. 2012 May;2(5):401-4.

24 Gao J, Aksoy BA, Dogrusoz U, Dresdner G, Gross B, Sumer SO, et al. Integrative analysis of complex cancer genomics and clinical profiles using the cBioPortal. Sci Signal. 2013 Apr;6(269):pl1.

25 Schulze K, Imbeaud S, Letouzé E, Alexandrov LB, Calderaro J, Rebouissou S, et al. Exome sequencing of hepatocellular carcinomas identifies new mutational signatures and potential therapeutic targets. Nat Genet. 2015 May;47(5):505-11.

26 Ahn SM, Jang SJ, Shim JH, Kim D, Hong SM, Sung CO, et al. Genomic portrait of resectable hepatocellular carcinomas: implications of RB1 and FGF19 aberrations for patient stratification. Hepatology. 2014 Dec;60(6): 1972-82.

27 Fujimoto A, Totoki Y, Abe T, Boroevich KA, Hosoda F, Nguyen HH, et al. Whole-genome sequencing of liver cancers identifies etiological influences on mutation patterns and recurrent mutations in chromatin regulators. Nat Genet. 2012 May;44(7):760-4.

28 Llovet JM, Villanueva A, Lachenmayer A, Finn RS. Advances in targeted therapies for hepatocellular carcinoma in the genomic era. Nat Rev Clin Oncol. 2015 Jul;12(7):408-24.

29 Huang Q, Lin B, Liu H, Ma X, Mo F, Yu W, et al. RNA-Seq analyses generate comprehensive transcriptomic landscape and reveal complex transcript patterns in hepatocellular carcinoma. PLoS One. 2011;6(10):e26168. 
Tsuge et al.: Fusion Transcripts in Hepatocellular Carcinoma

30 Kan Z, Zheng H, Liu X, Li S, Barber TD, Gong Z, et al. Whole-genome sequencing identifies recurrent mutations in hepatocellular carcinoma. Genome Res. 2013 Sep;23(9):1422-33.

31 Llovet JM, Bruix J. Molecular targeted therapies in hepatocellular carcinoma. Hepatology. 2008 Oct; 48(4): 1312-27.

32 Boyault S, Rickman DS, de Reyniès A, Balabaud C, Rebouissou S, Jeannot E, et al. Transcriptome classification of HCC is related to gene alterations and to new therapeutic targets. Hepatology. 2007 Jan;45(1):42-52.

33 Nowell PC, Hungerford DA. Chromosome studies in human leukemia. II. Chronic granulocytic leukemia. J Natl Cancer Inst. 1961 Nov;27:1013-35.

34 Nome T, Hoff AM, Bakken AC, Rognum TO, Nesbakken A, Skotheim RI. High frequency of fusion transcripts involving TCF7L2 in colorectal cancer: novel fusion partner and splice variants. PLoS One. 2014 Mar; 9(3):e91264.

35 Stephens PJ, McBride DJ, Lin ML, Varela I, Pleasance ED, Simpson JT, et al. Complex landscapes of somatic rearrangement in human breast cancer genomes. Nature. 2009 Dec;462(7276):1005-10.

36 Tomlins SA, Aubin SM, Siddiqui J, Lonigro RJ, Sefton-Miller L, Miick S, et al. Urine TMPRSS2:ERG fusion transcript stratifies prostate cancer risk in men with elevated serum PSA. Sci Transl Med. 2011 Aug;3(94):94ra72. Honeyman JN, Simon EP, Robine N, Chiaroni-Clarke R, Darcy DG, Lim II, et al. Detection of a recurrent DNAJB1PRKACA chimeric transcript in fibrolamellar hepatocellular carcinoma. Science. 2014 Feb;343(6174):1010-4.

38 Cornella H, Alsinet C, Sayols S, Zhang Z, Hao K, Cabellos L, et al. Unique genomic profile of fibrolamellar hepatocellular carcinoma. Gastroenterology 2015;148:806-818 e810.

39 Chen ZH, Yu YP, Tao J, Liu S, Tseng G, Nalesnik M, et al. MAN2A1-FER Fusion Gene Is Expressed by Human Liver and Other Tumor Types and Has Oncogenic Activity in Mice. Gastroenterology 2017;153:1120-1132 e1115.

40 Borad MJ, Gores GJ, Roberts LR. Fibroblast growth factor receptor 2 fusions as a target for treating cholangiocarcinoma. Curr Opin Gastroenterol. 2015 May;31(3):264-8.

41 Mertens F, Johansson B, Fioretos T, Mitelman F. The emerging complexity of gene fusions in cancer. Nat Rev Cancer. 2015 Jun;15(6):371-81.

42 Tobal K, Newton J, Macheta M, Chang J, Morgenstern G, Evans PA, et al. Molecular quantitation of minimal residual disease in acute myeloid leukemia with $\mathrm{t}(8 ; 21)$ can identify patients in durable remission and predict clinical relapse. Blood. 2000 Feb; 95(3):815-9.

43 Yang S, Wang X, Contino G, Liesa M, Sahin E, Ying H, et al. Pancreatic cancers require autophagy for tumor growth. Genes Dev. 2011 Apr;25(7):717-29.

44 Ding YP, Yang XD, Wu Y, Xing CG. Autophagy promotes the survival and development of tumors by participating in the formation of vasculogenic mimicry. Oncol Rep. 2014 May;31(5):2321-7.

45 Luo JH, Liu S, Zuo ZH, Chen R, Tseng GC, Yu YP. Discovery and Classification of Fusion Transcripts in Prostate Cancer and Normal Prostate Tissue. Am J Pathol. 2015 Jul;185(7):1834-45.

46 Baca SC, Prandi D, Lawrence MS, Mosquera JM, Romanel A, Drier Y, et al. Punctuated evolution of prostate cancer genomes. Cell. 2013 Apr;153(3):666-77.

47 Meyerson M, Pellman D. Cancer genomes evolve by pulverizing single chromosomes. Cell. 2011 Jan;144(1): 9-10.

48 Zhang DY, Friedman SL. Fibrosis-dependent mechanisms of hepatocarcinogenesis. Hepatology. 2012 Aug; 56(2):769-75.

49 Zhang H, Ozaki I, Mizuta T, Yoshimura T, Matsuhashi S, Eguchi Y, et al. Transforming growth factor-beta 1 -induced apoptosis is blocked by beta 1-integrin-mediated mitogen-activated protein kinase activation in human hepatoma cells. Cancer Sci. 2004 Nov;95(11):878-86.

50 Lai KK, Shang S, Lohia N, Booth GC, Masse DJ, Fausto N, et al. Extracellular matrix dynamics in hepatocarcinogenesis: a comparative proteomics study of PDGFC transgenic and Pten null mouse models. PLoS Genet. 2011 Jun;7(6):e1002147. 